\title{
Pattern of Annual Distribution and Prevalence of Type 2 Diabetes Mellitus amongst Adult Patients at Government House Clinic, Umuahia, Abia State, Nigeria: Ten Years in Retrospect
}

\author{
${ }^{1}$ Umezurike, B.C., ${ }^{2}$ Akhimien, M.O., ${ }^{1}$ Uma-Kalu, I. B., ${ }^{3,4}$ Ijioma, S.N., \\ ${ }^{3}$ Ogwo, E.U., ${ }^{1}$ Ezekwerem, C.M \\ ${ }^{1}$ Government House Clinic, Umuahia, Nigeria. \\ ${ }^{2}$ National Stop Transmission of Polio, Field Office, Gusau, Zamfara State, Nigeria. \\ ${ }^{3}$ Department of Human Physiology, Abia State University, Uturu, Nigeria. \\ ${ }^{4}$ Department of Physiology and Pharmacology, Michael Okpara University of Agriculture, Umudike, Nigeria.
}

\begin{abstract}
This study investigated the pattern of yearly frequency distribution, as well as annual prevalence rate of type 2 diabetes mellitus (T2DM) amongst adult patients attending diabetes clinics at Government house clinic, Umuahia, Nigeria over a period of ten years. This was carried out by a retrospective review of patients clinical records at the Clinic from 2006 to 2016. The ages of subjects ranged from 25 to 85 years, with a mean value of $55.0 \pm 12.80$ years and comprised of both males and females, diagnosed with T2DM. The study was a longitudinal and descriptive one. Results obtained indicated that of the 17482 patients which attended the clinic within the 10-year study period, a total of 764 were diabetic, representing a prevalence rate of $4.40 \%$ and showed progressive increments in yearly prevalence with time. There was however a non linear increase in frequency of between $1.0 \%$ and $28.3 \%$, with the first 6 years of study showing a gradual increase and the last 4 years showing a rapid increae in T2DM. The yearly prevalence also followed a similar pattern of non linear increment of between $0.9 \%$ and $7.1 \%$, with the first 6 years of study showing a gradual increase while the last 4 years showing a rapid increase in T2DM from 2006 to 2016.
\end{abstract}

Keywords: Fasting blood glucose, Hyperglycemia, Insulin, Metabolic disease, Type 2 Diabetes Mellitus, Umuahia.

\section{Introduction}

The American Diabetic Society (2009) $)^{1}$ had reported that diabetes mellitus (DM) was a group of metabolic diseases characterized by hyperglycemia resulting from defects in insulin secretion and insulin action, or both. The disease is clinically divided into two major types: Type 1 diabetes mellitus (T1DM), also known as insulin-dependent diabetes, or juvenile-onset diabetes, which results from cellular-mediated autoimmune destruction of the $\beta$-cells of the pancreas. ${ }^{2}$ In type 2 diabetes mellitus (T2DM) commonly called non-insulindependent diabetes or adult-onset diabetes, individuals have insulin resistance and usually have relative (rather than absolute) insulin deficiency. ${ }^{3,4}$ Most patients with T2DM are obese. Obesity itself causes some degree of insulin resistance. ${ }^{5}$ Patients who are not obese by traditional weight criteria may have an increased percentage of body fat distributed predominantly in the abdominal region. ${ }^{6}$ The risk of developing T2DM increases with age, obesity, and lack of physical activity. ${ }^{7}$ T2DM is often associated with strong genetic predisposition, more so than is the case with autoimmune form of T1DM. ${ }^{8}$ However, the genetic interplay in diabetes is complex and not clearly understood. Symptoms of marked hyperglycemia as seen in DM include: polyuria, polydipsia, weight loss, sometimes with polyphagia and blurred vision. ${ }^{9}$ Impairment of growth and susceptibility to certain infections may also accompany chronic hyperglycemia. Acute, life-threatening consequences of diabetes are hyperglycemia with ketoacidosis or the nonketotic hyperosmolar syndrome.

Both the International Diabetes Federation (IDF) and World Health Organization (WHO) have been providing estimates on the rise in diabetes cases worldwide since 1997. King et al., $(1998)^{\mathbf{1 0}}$, in there studies estimated that there were 135 million people globally with DM in 1995, and predicted that the number of cases may rise to a staggering 300 million by 2025 . The report of WHO Study Group (1994), ${ }^{11}$ on Prevention of diabetes mellitus had revealed that globally, the number of people with T2DM was rising rapidly. This rise was associated with population growth, economic development, ageing populations, increasing urbanization, dietary changes, obesity, reduced physical activity and changes in other lifestyle patterns ${ }^{\mathbf{1 0}}$. According to WHO $(2016)^{12}$, global report on diabetes, An estimated 422 million adults were living with diabetes in 2014, compared to 108 million in 1980 globally. The global prevalence (age-standardized) of diabetes has nearly doubled since 1980 , rising from $4.7 \%$ to $8.5 \%$ in the adult population. A published update on diabetes in Africa by the International Diabetes Federationin (2013), ${ }^{13}$ noted that the region was witnessing a surge in cases of DM, with a disease prevalence of $4.99 \%$ among those $20-79$ years. ${ }^{14}$ The majority of DM patients in the region were aged, 
60 years and more than $76 \%$ of deaths due to the disease occured in same age bracket. Peer et al., (2014), ${ }^{14}$ reported a prediction that Africa will witness a 110\% increase in prevalence of DM between 2013 and 2035, with most of the affected people suffering from T2DM. The International Diabetes Federation (IDF) ${ }^{15}$ estimates that over 5 million people suffer from the disease in Africa and the number is expected to increase to 15 million by 2025. The WHO (1994) ${ }^{11}$ report on Prevention of DM, says Nigeria has the greatest number of people living with diabetes in Africa, with an estimated burden of about 1.7 million, which will increase to 4.8 million by 2030. According to International Diabetes Federation Atlas $(2013)^{\mathbf{1 6}}$, Nigeria has the highest number of cases of DM, among countries in Africa, with 3.9million people (4.99\%) affected. In Nigeria, the national prevalence of $\mathrm{DM}$ is $2.2 \%$ with a higher prevalence in the urban than in the rural communities. ${ }^{17}$ This has increased from $2.2 \%{ }^{17}$ from a national survey to $5.0 \%$ by 2013 estimates of the International Diabetes Federation (IDF). ${ }^{17,16}$ Studies in Nigeria have also reported that the prevalence of diabetes varied across different zones of the country but ranges from $2.2-9.8 \% .{ }^{17},{ }^{18}$ Nigeria has the highest number of people living with diabetes and impaired fasting glucose (IFG) in Africa. ${ }^{15}$ According to report, it has been estimated that the number of people with diabetes in Nigeria is presently over 1.5 million and may be higher in the years ahead. ${ }^{19}$

A number of risk factors have been identified in the aetiology of diabetes mellitus including changes in lifestyle and physical inactivity, dietary pattern characterized by increased consumption of diets rich in saturated fats and high calories. ${ }^{20,21,22}$ It has also been reported that advancement in technology and urbanization are associated with these lifestyles and habits. ${ }^{20,22}$ Increasing socioeconomic empowerment has also been reported to be responsible for the increasing number of diabetic patients. ${ }^{23,24,22}$

Most patients with DM suffer from co-existing hypertension. Also all persons with hypertension, irrespective of age, sex, and body mass index (BMI), were at elevated risk of developing diabetes. ${ }^{25,26,22}$ In their seperate studies, Ogun (2005) ${ }^{27}$ and Umuerri (2013) ${ }^{28}$ found that Cardiovascular complications of DM such as stroke, and peripheral disease occured in $11 \%$ and $37 \%$ respectively of persons with DM respectively in hospital settings in Nigeria. However, $2.1 \%$ of cases of heart failure is noted to be due to DM. ${ }^{29} \mathrm{DM}$ and associated cardiovascular problems were worse in women than in men. Women were expected to have higher prevalence of DM and hypertension because they tend to become obessed more easily than men. ${ }^{30,31,22}$ Diabetes mellitus and hypertension are interrelated diseases that strongly predispose an individual to atherosclerotic cardiovascular disease. Hypertension is about twice as frequent in individuals with diabetes as in those without. Indeed, an estimated 35\% to $75 \%$ of diabetic cardiovascular and renal complications can be attributed to hypertension. ${ }^{32,33}$

Diabetic retinopathy exhibits a miotic pupil while significantly smaller pupils were found in people with proliferative diabetic retinopathy. ${ }^{34,35}$ Index myopia is the temporary or transient myopia in hyperglycemia, mostly in $\mathrm{T}_{2} \mathrm{DM}^{36}$. According to Duke Elder ${ }^{36}$ the refractive changes in diabetes are due to alterations in the power of the lens, because of osmotic interactions between the lens and aqueous. ${ }^{37}$ Index hyperopia occurs prior to the manifestation of the diabetes or after the reversal of the condition is achieved. With the variation of blood glucose, there is a tendency to hyperopia with decreased sugar. A hyperopic shift in refractive error, in a person with diabetes mellitus, is most likely to be due to Intensive glycemic control. Hyperopia seems not to occur as an initial phenomenon in diabetes but to follow myopic change ${ }^{36}$ Glucose and its metabolic products, especially those derived from the sorbitol pathway, accumulate within the lens. ${ }^{38}$ The resultant influx of water has been used to explain either a myopic or a hyperopic change, according to whether shape or refractive index, is considered more important in determining overall refractive power. ${ }^{39}$ Elliott and Pesudovs (2009) ${ }^{40}$; Kanski $(2007)^{41}$ noted two major types of diabetic cataracts: (1) True diabetic cataract, the more frequent adult-onset diabetic cataracts, similar in appearance to nuclear sclerosis cataracts. (2) The 'snowflake' cataracts, characterized by flake opacities and fine white punctuate spots in the anterior and posterior subcapsular areas of the lens, reversible once the hyperglycemic condition is reversed.

A number of Kidney problems have also been associated with diabetes mellitus. ${ }^{27,}$ 28, 42 Peripheral neuropathy is also a complication related to hyperglycemia. ${ }^{43},{ }^{44}$ Patients with T2DM are at increased risk of developing macrovascular and microvascular complications, ${ }^{45,}{ }^{46}$ as well as sexual dysfunction. Akanji and Adetuyibi $(1990)^{43}$ reported that diabetic foot ulcer, of which one third would result in amputation, results to $30 \%$ of mortality cases from DM. In Nigerian study, gestational diabetes occur in 2.98 per 000 pregnancies, ${ }^{47}$ while in another study, it showed that the prevalence increased with maternal age; $3.3 \%$ in the age group of 15 to 24 years, $4.2 \%$ in those aged 25 to 34 years with a spike to $17.6 \%$ in the age group of 34 to 44 years and an average prevalence of $4.2 \%{ }^{48}$

Hyperglycemia in T2DM is controlled primarily by diet and oral hypoglycemic agents ${ }^{49}$ although insulin may also be required when diet and tablet therapy fail to induce blood glucose homeostasis.Due to paucity of published materials on the prevalence of DM in Abia State, Nigeria, this study was designed to examine the pattern and variations in the annual frquency distribution of T2DM as well as its annual prevalence rates for patients of age range of betwee 25 and 75 years who attended Government House Clinic, Umuahia. Nigeria from 2006 to 2016 . 


\subsection{Study design}

\section{Methodology}

This is a longitudinal and descriptive study, to evaluate the pattern of yearly frequency distribution and trend in the prevalence of T2DM, from 2006 to 2016, at the Government House Clinic, located in Abia State, South East of Nigeria. This entailed a retrospective review of the patients clinical records, from the documentations and yearly statistical summary of the clinical activities, within the said period. The selection criteria was opened to all registered patients who attended Government House Clinic, Umuahia, Nigeria, within the period of study, irresspective of gender and whose age were within the age range under study, and were diagnosed with T2DM. Data collected were for: The study period / duration in years, the frequency of T2DM in perentage and the prevalence of T2DM in percentage. However, follow up cases during the period under review were not considered as new cases. Ethical approval and clearance was obtained from the Health Research and Ethics Committee of Government House Clinic, Umuahia, Abia state, Nigeria.

\subsection{Sample size}

The sample was made up of 764 patients diagnosed of type 2 diabetes mellitus drawn from the total population sample of patients clinical records of about 17482 patients that attended the clinic from 2006 to 2016, aged from 25 years to 85 years. The sample size was based on the total population of the patients between the ages of 25 yearrs and 85 years, with a mean ( \pm standard deviation) of the study population of about $55.0 \pm$ 12.3 years within the study period.

\subsection{Diagnostic criterion}

The diagnostic criterion for diabetes was according to the World Health Organization (WHO) (2006) recommendations for the diagnosis of diabetes and intermediate hyperglycaemia ${ }^{50}$ : In a fasting state (Fasting plasma glucose $\geq 7.0 \mathrm{mmol} / \mathrm{L}(126 \mathrm{mg} / \mathrm{dl})), 2$ hours after a $75 \mathrm{~g}$ oral load of glucose has been taken (2h plasma glucose $\geq 11.1 \mathrm{mmol} / \mathrm{L}(200 \mathrm{mg} / \mathrm{dl})$ ) or measuring glycated haemoglobin $(\mathrm{HbA} 1 \mathrm{c} \geq 6.5 \%)$. The baseline for the diagnosis of DM were as given depending on the result of the test chosen, and individuals whose normal glycemic values were above the threshold were considered diabetic.

\subsection{Statistical analysis}

Computer software package, SPSS version 17 was employed. The data obtained was organized and presented as graphs in form of a histogram. The necessary statistical procedure and the analysis of the results were expressed as mean \pm standard deviation (SD).

\section{Results}

Of the 17482 patients seen at the clinic within the 10 - year study period, a total of yearly frequency of 764 T2DM was recorded, with a prevalence rate of $4.4 \%$. The trend however demonstrated a yearly rise in both frequency and prevalence within the study period. The yearly frequency distribution of T2DM recorded over the 10 - year period under study also had direct relationship with its associated prevalence (Table 1). There was annual increment in the frequency distribution of T2DM which was not linear in relationship with the years within the 10 - year study period. From 2006 to 2012, gradual increase in frequency was observed while from 2013 to 2016 the increament was rapid and higher (Fig 1). There was also a gradual increase in the prevalence of T2DM over the years but the pattern of yearly increment was also non linear in relationship, as the results indicated that from 2006 to 2012, the prevalence rate increased gradually, while from 2013 to 2016, it was rapid and higher (Fig 2).

Table 1: The annual percentage frequency distribution and prevalence of type 2 diabetes mellitus from 2006 to 2016

\begin{tabular}{|l|l|l|l|l|}
\hline Years & $\begin{array}{l}\text { Population } \\
\text { Size }\end{array}$ & $\begin{array}{l}\text { Frequency Of Type 2 } \\
\text { Diabetes }\end{array}$ & $\begin{array}{l}\text { Percentage } \\
\text { Frequency Of Type 2 } \\
\text { Diabetes (\%) }\end{array}$ & $\begin{array}{l}\text { Prevalence Of Type } \\
\text { 2 Diabetes (\%) }\end{array}$ \\
\hline 2006 & 860 & 8 & 1.0 & 0.9 \\
\hline 2007 & 940 & 10 & 1.3 & 1.1 \\
\hline 2008 & 1002 & 21 & 2.7 & 2.1 \\
\hline 2009 & 1240 & 23 & 3.0 & 1.9 \\
\hline 2010 & 951 & 18 & 2.4 & 1.9 \\
\hline 2011 & 980 & 24 & 3.1 & 2.4 \\
\hline 2012 & 1020 & 28 & 3.7 & 2.7 \\
\hline 2013 & 1350 & 47 & 6.2 & 3.5 \\
\hline 2014 & 3039 & 166 & 21.7 & 5.5 \\
\hline 2015 & 3048 & 203 & 26.6 & 6.7 \\
\hline 2016 & 3052 & 216 & 28.3 & 7.1 \\
\hline Total & 17482 & 764 & 100 & 4.4 \\
\hline
\end{tabular}



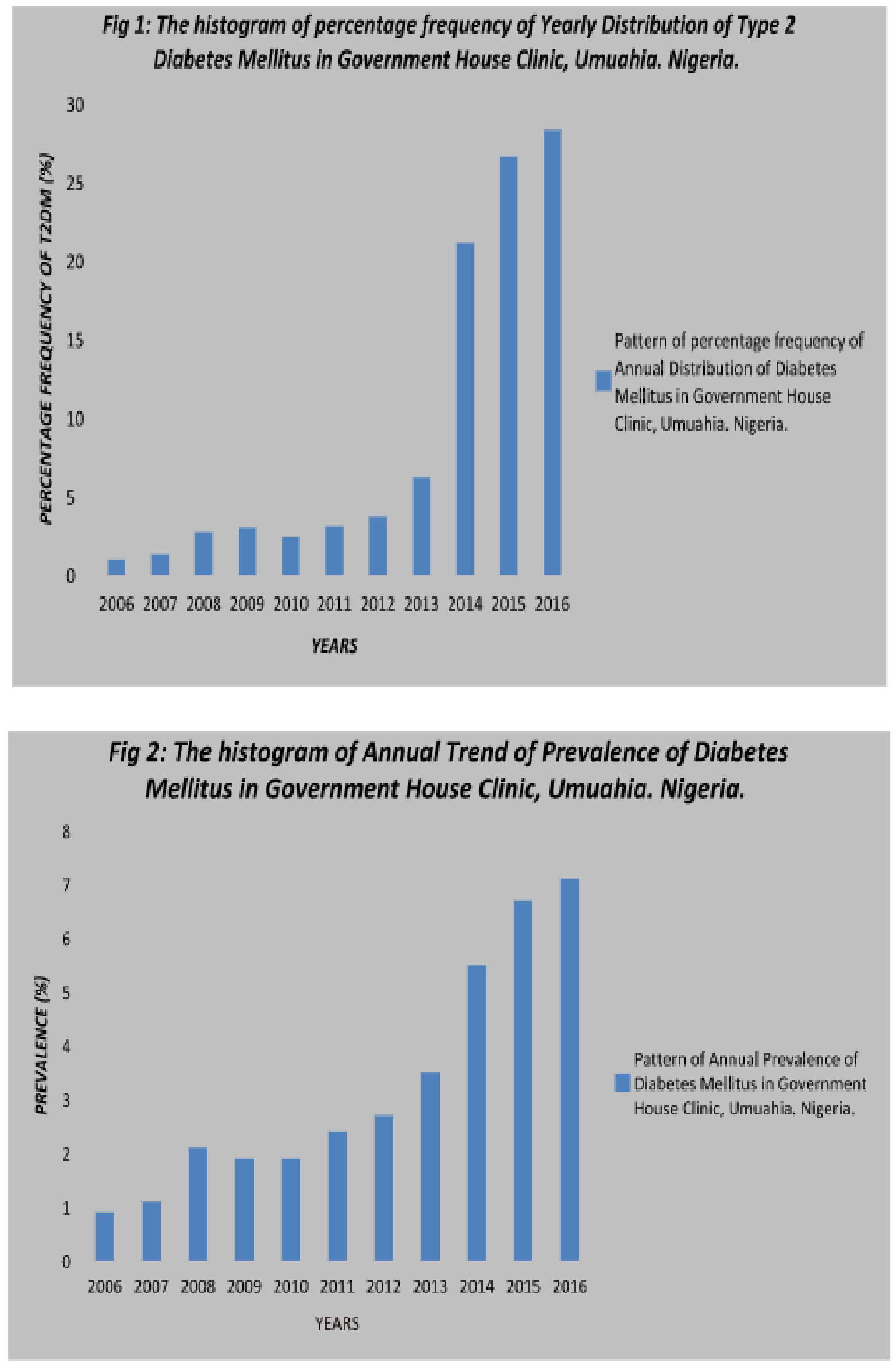


\section{Discussion}

In this study, the pattern of increment in the yearly frequency distribution of T2DM agreed with the WHO's ${ }^{11}$ Study Group report on Prevention of diabetes mellitus, which showed that globally, the number of people with T2DM was on rapid increase due to population growth, economic development, ageing populations, increasing urbanization, dietary changes, obesity, reduced physical activity and changes in other lifestyle patterns. ${ }^{\mathbf{1 0}}$ This study also showed a non linear increment in prevalence of T2DM between 2006 and 2016, consistent with the report of the findings of Chijioke et al., (2010). ${ }^{\mathbf{5 1}}$ and Murray and Lopez (1997), ${ }^{\mathbf{5 2}}$ that prevalence of DM in adults will increase in the next two decades and much of the increament will occur in developing countries, where the majority of patients were aged between 45 and 64. This was further corroborated by the prediction of Wild et al., (2004), ${ }^{\mathbf{5 3}}$ that the prevalence of DM globally, which was such that the number of people over the age of 20 years with the condition, was estimated to be 171 million during the year 2000, and is projected to rise by almost three-fold in the year 2030 due to population growth, increased life expectancy and altered diets and living.

The yearly fluctuations in the pattern of increament and variation in prevalence of T2DM from this study may be attributed to the location of the patients, either urban or rural communities. This trend was also demonstrated by the report of Akinkugbe (1997), ${ }^{17}$ that the prevalence in Nigeria varies from $0.65 \%$ in rural area (Mangu, Northern Nigeria) to $11 \%$ in urban Lagos (Lagos, Southern Nigeria); and with and Motala (2002), ${ }^{\mathbf{5 4}}$ that in Africa, the estimated prevalence of diabetes is $1 \%$ in rural areas, up to $7 \%$ in urban sub-Sahara Africa, and between $8-13 \%$ in more developed areas such as South Africa.

Factors responsible for the increased prevalence of T2DM in Nigeria as revealed in this study include lifestyle, age, socioeconomic, demographic, poor health infrastructure, etc. This was in line with the submission of Ogbera and Ekpebegh (2014), ${ }^{\mathbf{5 5}}$ that the key issues with regards to diabetes in the future relate to the increasing population of Nigerians, increasing life expectancy of Nigerians, projected increase in the incidence and prevalence of diabetes, low per capita income of most Nigerians, poorly developed health care infrastructure and the current situation where the predominant means of procuring health services is "out of pocket" payment. This was also in line with Sobnigwe et al., (2001), ${ }^{\mathbf{5 6}}$ with the report that "the prevalence of diabetes mellitus and other non-communicable diseases is on the rise in African communities due to the ageing of the population and drastic lifestyle changes and accompanying urbanization and westernization'. These causative factors were also substantiated by the findings of Umezurike et al., (2016a), ${ }^{57}$ that the dietary habbits, lifestyle, alcohol consumption and lack of exercise being the major risk factors, that influenced most non communicable diseases especially hypertension and diabetes.

\section{Conclusion}

The past ten years under study (2006 to 2016) witnessed an increase in frequency and prevalence of T2DM. There was no consistency in the pattern of these increament, but rather a non linear pattern was demonstrated. These were apparently gradual initially, but rapid and sustained in the last 4 years of the study. This could be attributed to a change in life style towards western culture and diet in recent time on one hand; and more enlightenment and awareness on the need to attend diabetic clinic for screening and treatment on the other hand.

\section{References}

[1]. American Diabetes Association. Diagnosis and Classification of Diabetes Mellitus, Diabetes Care, 32 (Suppl 1), 2009 , S62-S67.

[2]. Atkinson, M.A., Maclaren, N.K., The pathogenesis of insulin dependent diabetes. N Engl J Med, 331, 1994, 1428-1436.

[3]. Reaven, G.M., Bernstein, R., Davis, B., Olefsky, J.M., Nonketotic diabetes mellitus: insulin deficiency or insulin resistance? Am J Med 60, 1976, 80-88.

[4]. DeFronzo, R., Deibert, D., Hendler, R., Felig, P., Insulin sensitivity and insulin binding to monocytes in maturity-onset diabetes, J Clin Invest, 63, 1979, 939-946.

[5]. Bogardus, C., Lillioja, S., Mott, D.M., Hollenbeck, C., Reaven, G., Relationship between degree of obesity and in vivo insulin action in man, Am J Physiol, 248, 1985, E286-E291.

[6]. Kissebah, A.H., Vydelingum, N., Murray, R., Evans, D.F., Hartz, A.J., Kalkhoff, R.K., Adams, P.W., Relationship of body fat distribution to metabolic complications of obesity, J Clin Endocrinol Metab, 54, 1982, 254-260.

[7]. Harris, M.I., Couric, C.C., Reiber, G., Boyko, E., Stern, M., Bennett, P., Diabetes in America. 2nd ed. Washington, DC, U.S. Govt. Printing Office. (1995, NIH publ. no. 95-1468).

[8]. Newman, B., Selby, J.V., Slemenda, C., Fabsitz, R., Friedman, G.D., Concordance for type 2 (non-insulin-dependent) diabetes mellitus in male twins. Diabetologia, 30, 1987, 763-738.

[9]. American Diabetes Association, Expert Committee on the Diagnosis and Classification of Diabetes Mellitus,.2016.

[10]. King H., Aubert R. E., Herman W. H., Global Burden of Diabetes. Prevalence, Numerical Estimates and Projections. Diabetes Care. 21, 1998, 1414-31. [PubMed: 9727886].

[11]. World Health Organization, Prevention of diabetes mellitus. Report of a WHO Study Group No. 844. Geneva: World Health Organization; 1994.

[12]. World Health Organization (WHO), Geneva, Global Report on Diabetes, 2016.

[13]. International Diabetes Federation (IDF). Diabetes Atlas. 6th Edition, International Diabetes Federation, 2013, Available at: 
http://www.idf.org/diabetesatlas.

[14]. Peer, N., Kengne, A.P., Motalac, A.A., Mbanya, J.C., IDF Diabetes Atlas. Diabetes in the Africa region: An update. Diabetes Res Clin Pract, 103(2), 2014, 197-205.

[15]. International Diabetes Federation. Diabetes Fact Sheet. Available at www.idf.org/webdata/docs/background_info _ AFR. pdf.

[16]. International Diabetes Federation. 3rd ed 2006. The improved Diabetes Atlas.

[17]. Akinkugbe, O.O. (Ed.), Non-Communicable Diseases in Nigeria: National Survey (Final Report) on Hypertension, Coronary Heart Disease, Diabetes Mellitus, Haemoglobinopathies, G6PD defciency and Anaemia. National Expert Committeeon NonCommunicable Disease. Lagos, Nigeria: Federal Ministry of Health and Social Services. Lagos. 1997.

[18]. Nyenwe, E.A., Odia, O. J., Ihekwaba A, E., Ojule, A., Babalola S., Type 2 diabetes in adult Nigerians: A study of its prevalence in Port Harcourt, Nigeria, Diabetes Res Clin Pract. 62, 2003, 177- 185.

[19]. Adefemi, K. What you need to know about diabetes. Available at http://ezine articles.com/? What-You-Need-To-Know-AboutDiabetes\&id=22656, 2009.

[20]. Das, S. K.; Sanyal, K.; Basu, A., Study of urban community survey in India: growing trend of high prevalence of hypertension in a developing country. International Journal of Medical Science. 2, 2005, 70-8.

[21]. Umezurike, B.C., Akhimien, M.O., Ogwo, E.U., Ijioma, S.N., Uma-Kalu, I. B., Prevalence of Hypertension Amongst adults in Ikwuano Local Government Area of Abia State, Nigeria : A Survey. Researchjournali's Journal of Public Health, 2 (9), $2016 \mathrm{~b}, 1$ 8 .

[22]. Umezurike, B.C., Akhimien, M.O., Ogwo, E.U., Ijioma, S.N., Uma-Kalu, I. B., Hypertension and its Comparative Prevalence Rates Amongst Adults in Umunneochi and Ikwuano Local Government Areas of Abia State, Nigeria. Researchjounali's journal of Public Health, 2 (11), 2016c, 1 -14.

[23]. Mendez, M.A., Cooper, R., Wilks, R., Luke, A., Forrester, T., Income, education, and blood pressure in adults in Jamaica, a middle-income developing country. International Journal of Epidemiology, 32, 2003, 400-408.

[24]. Reddy, K. S. and Yusuf S., Emerging epidemic of cardiovascular disease in developing countries, Circulation; 96, 1998, 596601.

[25]. Mengesha, A.Y., Hypertension and related risk factors in type 2 diabetes mellitus (DM) patients in Gaborone City Council (GCC) clinics, Gaborone, Botswana, Afr Health Sci, 7(4), 2007, 244-245.

[26]. Weycker, D., Nichols, GA., O'Keeffe-Rosetti, M., Edelsberg, J., Vincze, G., Khan, Z.M., Oster, G., Excess risk of diabetes in persons with hypertension, J Diabetes Complications, 23(5), 2009, 330-6.

[27]. Ogun, S.A., Ojini, F.I., Ogungbo, B., Kolapo, K.O., Danesi, M.A., Stroke in south west Nigeria: a 10-year review, Stroke. 36, $2005,1120-1122$

[28]. Umuerri, E.M., Obasohan, A.O., Lower extremity peripheral artery disease: prevalence and risk factors among adult Nigerians with diabetes mellitus, West Afr J Med. 32, 2013, 200-205.

[29]. Onwuchekwa, A.C., Asekomeh. G.E., Pattern of heart failure in a Nigerian teaching hospital, Vasc Health Risk Manag, 5, 2009, 745-750.

[30]. Muhammed, A.S., Manna, F.K., Thomas, E.C., Cardiovascular problems in diabetes mellitus. Mater Sociomed., 25(2), 2013, 40142.

[31]. Esayas, H.H., Hiroshi, Y., Leo, k., and Atsuko, A., Diabetes mellitus and women, Bulletin of World Health Organisation, 91, 2013, 671-682.

[32]. Epstein, M., Sowers, J.R., Diabetes mellitus and hypertension, Hypertension. 19, 1992, 403-418.

[33]. National High Blood Pressure Education Program Working Group, Report on hypertension in diabetes, Hypertension, 23 (2), $1994,45-158$

[34]. Smith, S.E., Smith, S.A., Brown, P.M., Fox, C., Sonksen, P.H, Pupillary signs in diabetic autonomic neuropathy, British Medical Journal, 2, 1978, 924-927.

[35]. Hayashi, K., Hayashi, H., Pupil size before and after phacoemulsification in nondiabetic and diabetic patients. Journal of Cataract and Refractive Surgery, 30, 2004, 2543-2550.

[36]. Duke-Elder, S., System of Ophthalmology, (London: Kimpton, 1970) 5, 368-70.

[37]. Sorsby A., Modern Ophthalmology, (Philaldelphia Lippincott. 1972) 3, 33

[38]. rooks, M.H., Lenticular abnormalities in endocrine dysfunction. In: Bellows JG, ed.Cataract and Abnormalities of the Lens, (St Louis: Mosby, 1975) 285-6.

[39]. Moses, R.A, Adler's Physiology of the Eye Clinical Application (St Louis: Mosby, 296, 1981)

[40]. Elliott, D.B., Pesudovs, K., Variations in appearance of the normal ocular media,. Optometry Today, 49 (24), 2009, 30-37.

[41]. Kanski, J.J., Clinical Ophthalmology; A systematic approach (6th edition, Elsevier, pp341,.2007)

[42]. Sowers, J.R. and Epstein, M., Diabetes Mellitus and Associated Hypertension, Vascular Disease, and Nephropathy. An Update. HYP.26, (6), 1995, 869.

[43]. Akanji, A.O., Adetuyibi, A., The pattern of presentation of foot lesions in Nigerian diabetic patients, West Afr J Med. 9, 1990, 15 .

[44]. Ogbera, A.O., Chineneye, S., Onyekwere, A., Fasanmade, O., Prognostic Indices of DM mortality Ethn Dis. 17(4), 2007, 721725.

[45]. Haynes, A., Bulsara, M.K., Bower, C., Codde, J.P., Jones, T.W., Davis, E.A., Independent effects of socioeconomic status and place of residence on the incidence of childhood type 1 diabetes in Western Australia, Pediatr Diabetes, 7, 2006, 94-100.

[46]. Kitabchi, A.E., Umpierrez, G.E., Murphy, M.B., Barrett, E.J., Kreisberg, R.A., Malone, J.I., et al., Hyperglycemic crises in patients with diabetes mellitus, Diabetes Care. 26 Suppl 1, 2003, S109-17.

[47]. Wokoma, F.S., John, C.T., Enyindah, C.E., Gestational diabetes mellitus in a Nigerian antenatal population, Trop J Obstet Gynaecol. 18, 2001. 56-60.

[48]. Ewenighi, C.O., Nwanjo, H.U., Dimkpa, U., Onyeanusi, J.C., Nnatuanya, I.N., Onoh, L.U.M., Prevalence of Gestational Diabetes Mellitus; Risk factors among pregnant women in Abakaliki metropolis Ebonyi State Nigeria, NJIRM. 4, 2013, 56-61.

[49]. Inzucchi, S.E., Oral anti-hyperglycaemic therapy for type 2 diabetes: scientific review. Journal of the American Medical Association, 287, 2002, 360-372.

[50]. World Health Organization (WHO) recommendations for the diagnosis of diabetes and intermediate hyperglycaemia, 2006.

[51]. Chijioke, A., Adamu, A.N., Makusidi, A.M., Mortality pattern among type 2 diabetes patients in Ilorin, Nigeria. JEMDSA. 15(2), 2010,.00-00.

[52]. Murray, C.J.L., Lopez, A.D,.Alternative projections of mortality and disability by cause. 1990-2020, Global burden of disease study. Lancet, 349, 1997, 1498-1504.

[53]. Wild S, Roglic G, Green A, Sicree R, King H., Global prevalence of diabetes: Estimates for the year 2000 and projections for 
2030. Diabetes Care. 27, 2004, 1047-53. [PubMed].

[54]. Motala, A.A., Diabetes Trends in African. Diabetes metab Res Rev 8, 2002, 514-520.

[55]. Ogbera, A.O. and Ekpebegh, C., Diabetes mellitus in Nigeria: The past, present and future. World J Diabetes. 5(6), 2014, 905911.

[56]. Sobnigwe, E., Mauvais-Jarvis, F., Vexiau P., Mbanya, J.C., Gautier, J.F., Diabetes in Africans; epidemiology and clinical specifcities. Diabetes Metab. 27, 2001, 6.

[57]. Umezurike, B.C., Ogwo, E.U., Akhimien, M.O., Ijioma, S.N., Uma-Kalu, I. B., Prevalence of Hypertension Amongst adults in Umunneochi Local Government Area of Abia State, Nigeria : A Survey, Journal of Current Research, 8 (4), 2016a, 29530-29533. 